\title{
Serum level of brain-derived neurotrophic factor in patients with relapsing-remitting multiple sclerosis: a potential biomarker for disease activity
}

\author{
Mohammed I. Oraby ${ }^{1 *}$ (D, Hatem A. El Masry ${ }^{1}$, Sanaa S. Abd El Shafy ${ }^{2}$ and Esraa M. Abdul Galil ${ }^{1}$
}

\begin{abstract}
Background: Brain-derived neurotrophic factor (BDNF) is secreted by immune cells in response to neuroimmune and inflammatory cascades as an act to prevent axonal and neuronal damage after various pathological insults. The serum level of BDNF is altered in a diversity of neurological diseases. The aim of this work was to investigate the serum level of BDNF in patients with relapsing-remitting multiple sclerosis and the relation between BDNF and disease activity and severity.

Methods: A case-control study was conducted on 90 subjects: 60 patients with relapsing-remitting multiple sclerosis (30 in relapse and 30 in remission) on different lines of medical treatment and 30 healthy volunteers as a control. Clinical, functional, and radiological evaluation was done for the patients, and all the patients and controls were subjected to assessment of the serum level of BDNF by sandwich-ELISA technique.

Results: The BDNF level was significantly higher in MS patients in relapse than in patients in remission ( $P$ value $=$ 0.006). In the remission group, there was no significant linear correlation between different MS patients' characteristics and BDNF level, while in the relapse group, a positive linear correlation was found between the number of T2 infratentorial lesions and BDNF level $(r=0.402, P=0.028)$. There was no statistically significant difference between the BDNF level in patients administered different drugs for MS in both remission and relapse groups ( $P$ value $>0.05$ ).

Conclusion: BDNF was significantly higher in relapsing-remitting multiple sclerosis patients in the relapse phase. Attention should be paid to the link between serum BDNF level as a neuroprotective factor and multiple sclerosis; it can be a biomarker for MS activity in the near future.
\end{abstract}

Keywords: Multiple sclerosis, Brain-derived neurotrophic factor, Neurotrophins, Expanded Disability Status Scale

\section{Introduction}

Multiple sclerosis is one of the most common neurological disorders in young adults. It is a chronic disease which is manifested by inflammation, demyelination, and axonal loss and most probably leads to a significant degree of disability [1].

\footnotetext{
* Correspondence: Drm_Oraby@med.bsu.edu.eg; Drm_Oraby@hotmail.com ${ }^{1}$ Neurology Department, Beni-Suef University, Beni-Suef 62511, Egypt Full list of author information is available at the end of the article
}

The chronic inflammation in multiple sclerosis pathology contradicts immune mechanisms that modulate and confine the inflammatory cascade to limit irreversible demyelination and axonal damage [2].

Brain-derived neurotrophic factor (BDNF) was cloned in 1989 [3]. After nerve growth factor, BDNF is the second recognized member in the neurotrophin family. It is an activity-dependent secreted protein which is expressed widely in the central nervous system and implicated in the differentiation, survival, and growth of 
neurons. Also, it is crucial to synaptic plasticity and neuronal network organization in animal models and in humans [4].

Accumulating imaging and immunohistological studies confirm the critical role of axonal injury in determining the magnitude of irreversible neurological deficits in MS patients. In humans, immune cells are capable of producing BDNF which can guard against neuronal damage and axonal injury following diverse pathological insults [5]

The serum level of BDNF is altered in a diversity of neurological diseases: patients with Alzheimer's disease [6] and patients with Parkinson's disease [7] had lower BDNF levels when compared to healthy controls that correlate with the disease severity. Several studies assessed the serum levels of BDNF in multiple sclerosis patients with conflicting results [8]. Till now, there is no definite cure for MS, and recent remyelination and/or myelin repair strategies are focusing on the potential role of the neurotrophin (BDNF) [9].

The aim of this work was to investigate the serum levels of BDNF in relapsing-remitting multiple sclerosis (RRMS) patients and the relation between BDNF and disease activity and severity.

\section{Methods}

This study is a case-control study conducted on 90 subjects: sixty patients with relapsing-remitting multiple sclerosis diagnosed according to the International Panel on Diagnosis of Multiple Sclerosis "McDonald's criteria 2017" [10] (30 in relapse and 30 in remission) on different lines of medical management. Relapse was defined as a monophasic clinical episode with patient-reported symptoms and objective findings typical for multiple sclerosis, reflecting a focal or multifocal inflammatory demyelinating event in the CNS, developing acutely or subacutely, with a duration of at least $24 \mathrm{~h}$, with or without recovery, and in the absence of fever or infection in a patient who had been neurologically stable or improving for the previous 30 days [10].

And 30 healthy volunteers free of any medical disease from the same geographical area were included. The multiple sclerosis patients and the controls were matched regarding age and gender. Informed written consent was taken from all subjects included in this study. And the study was approved by the authorized ethical committee.

All the patients included in this study were subjected to the following patterns of assessment: history takingfocusing on risk factors including family history and environmental, infectious, and clinical course of previous attacks-and thorough general and neurologic examination and the assessment of neurological impairment by Expanded Disability Status Scale (EDSS) [11].
The patient group also underwent magnetic resonance imaging (MRI) for the brain and spinal cord using 1.5-T Simens Scanner Magnetom Aera MRI, made in Germany. The following MRI protocols were used: T1weighted images, gadolinium-enhanced T1-weighted sagittal and axial and sagittal images for patients with clinical attacks at the time of assessment, T2-weighted images, and fluid-attenuated inversion recovery (FLAIR) sequence.

Blood samples were taken from patients and controls to measure the serum level of brain-derived neurotrophic factor (BDNF) (in MS patients with relapse, the blood samples were taken within 2 days from the onset of relapse and before the start of methylprednisolone pulse therapy). Sat fax automated ELISA system, made in the USA, 2010, was used. This ELISA kit used the sandwich-ELISA technique. The microElisa strip plate provided in the kit has been pre-coated with an antibody specific to BDNF. Samples were added to the appropriate microElisa strip plate wells and combined to the specific antibody. Then a horseradish peroxidase (HRP)conjugated antibody specific for BDNF was added to each microElisa strip plate well and incubated. Free components were washed away. Only those wells that contain BDNF and HRP-conjugated BDNF antibody appeared blue in color and then turned yellow after the addition of the stop solution. The optical density (OD) was measured spectrophotometrically at a wavelength of $450 \mathrm{~nm}$. The OD value was proportional to the concentration of BDNF in the samples by comparing the OD of the samples to the standard curve. Measuring range was $28-1000 \mathrm{pg} / \mathrm{ml}$.

\section{Statistical analysis}

Data was coded and entered using Microsoft Office Excel 2010. Statistical analysis was done using IBM SPSS version 24 (IBM Corporation, USA, Armonk, New York, 2016). Frequencies (number) and relative frequencies (percent) were used to summarize qualitative variables. Quantitative variables were tested for normality, normally distributed variables were summarized using mean and standard deviation, and comparison between groups was done using an independent sample $t$ test, while not normally distributed variables were summarized using median and quartiles and comparison between groups was done using the Mann-Whitney test and Kruskal-Wallis test followed by Mann-Whitney test (pairwise comparison). Pearson and Spearman rho (according to the normality of variables) correlations were used to test for possible correlations between quantitative variables. A $P$ value less than or equal to 0.05 was considered significant. 


\section{Results}

This study included 60 Egyptian patients with relapsingremitting multiple sclerosis (30 in relapse and 30 in remission) and 30 healthy volunteers free of any medical disease from the same geographical area as a control. The multiple sclerosis patients and the controls were matched regarding age and gender (Table 1).

The clinical characteristics of MS patients including the age of onset, duration of the disease, number of relapses in the last 2 years, total number of relapses, degree of disability measured by Expanded Disability Status Scale (EDSS), and type of disease-modifying therapy are shown in Table 2.

Table 3 shows the results of the serum BDNF level of 30 MS patients in remission and 30 MS patients in relapse and 30 healthy controls; there was no statistically significant difference between patients in relapse and controls or between patients in remission and controls ( $P$ value $=0.074$ and 0.870 , respectively), but the BDNF was significantly higher in patients in relapse than in patients in remission $(P$ value $=0.006)$.

Receiver operating characteristic (ROC) curve analysis was used to assess the sensitivity and specificity of BDNF in predicting MS activity (Fig. 1). The optimal cutoff value of BDNF that predicted disease activity was $\geq 265$ $\mathrm{pg} / \mathrm{ml}$, with a sensitivity of $80 \%$ and a specificity of $66.7 \%$ (the area under the curve $0.755,95 \%$ confidence interval 0.631 to $0.879, P$ value $=0.001$ )

Table 4 shows the correlation between different characteristics of MS patients and BDNF level; in the remission group, there was no significant linear correlation between different MS patients' characteristics and BDNF level, while in the relapse group, there was a positive linear correlation between the number of $\mathrm{T} 2$ infratentorial lesions and BDNF level $(r=0.402, P=0.028)$.

We studied the effect of MS therapy on BDNF level. There was no statistically significant difference between the BDNF level in patients administered different drugs for MS in both remission and relapse groups ( $P$ value $>$ 0.05) (Table 5).

\section{Discussion}

The etiology of MS is still not well known, and the interaction between environmental, genetic, and other factors that trigger an abnormal autoimmune cascade leads to demyelination and axonal injury [12].
BDNF is secreted by immune cells in response to inflammatory and neuroimmune cascades as a trial to guard against neuronal and axonal damage after various pathological insults [5]. BDNF regulates the relation between the immune and the nervous systems and plays a crucial role in brain-related disorders [13].

The aim of the present study was to assess the association between serum BDNF level and disease activity and severity in patients of relapsing-remitting MS.

This study was conducted on 60 MS patients: thirty patients in relapse, thirty patients in remission, and 30 control subjects. Assessment of the serum BDNF level was done for both MS patients and control groups. The serum level of BDNF was significantly higher in MS patients in relapse than those in remission. Using the ROC curve, the optimal cutoff value of BDNF that predicted disease activity was $\geq 265 \mathrm{pg} / \mathrm{ml}$, with a sensitivity of $80 \%$ and a specificity of $66.7 \%$.

Similar to our findings, Sarchielli and colleagues [14] assessed the BDNF level in their RRMS patients during attacks and 3 months after relapse and found significantly higher BDNF levels during relapse compared to levels detected in the remission state of the disease. Additionally, Frota and colleagues [15] found that levels of BDNF in MS patients increased significantly after MS relapse. Bruck and Stadelmann [12] studied the pathology of multiple sclerosis and reported that BDNF may promote remyelination, and this can support its increase during relapse.

In our study, there was no statistically significant difference between patients in relapse and control or between patients in remission and control. Similar to our findings, Sarchielli and colleagues [14] found that levels of BDNF in the RRMS patients in a remission phase did not differ from those of control subjects.

In contrast to our results, many studies found that BDNF levels in MS patients were significantly lower than those in the healthy control group [16-18]. The low BDNF secretion from immune cells of MS patients may be related to reduced neuroprotection [19]. As a result, low BDNF levels are expected to diminish the potentials for remission in MS patients and induce the progressive phase of the disease [20].

Also, Al-Temaimi and colleagues [21] found that BDNF levels were significantly lower in MS patients compared to healthy controls. They concluded that

Table 1 Age and sex distribution in MS cases and controls

\begin{tabular}{|c|c|c|c|c|c|}
\hline & & MS cases in remission $(n=30)$ & MS cases in relapse $(n=30)$ & Controls $(n=30)$ & $P$ value \\
\hline \multicolumn{2}{|c|}{ Age [mean \pm SD] } & $31.5 \pm 7.7$ & $30.9 \pm 8.4$ & $29 \pm 7.8$ & 0.312 \\
\hline \multirow[t]{2}{*}{ Sex } & Females $[n(\%)]$ & $18(60 \%)$ & $17(56.7 \%)$ & $16(53.3 \%)$ & 0.873 \\
\hline & Males [n (\%)] & $12(40 \%)$ & $13(43.3 \%)$ & $14(46.7 \%)$ & \\
\hline
\end{tabular}


Table 2 The baseline clinical characteristics of MS patients

\begin{tabular}{|c|c|c|c|}
\hline Clinical characteristics & MS cases in remission $(n=30)$ & MS cases in relapse $(n=30)$ & $P$ value \\
\hline Age of onset (years) & & & 0.938 \\
\hline Mean \pm SD & $26.5 \pm 7.7$ & $26.6 \pm 7.1$ & \\
\hline Range (min-max) & $(15-40)$ & $(15-44)$ & \\
\hline Duration of illness (years) & & & 0.478 \\
\hline Mean \pm SD & $5.1 \pm 4.7$ & $4.3 \pm 4.3$ & \\
\hline Range (min-max) & $(1-17)$ & $(1-18)$ & \\
\hline Number of relapses in the last 2 years & & & 0.580 \\
\hline Mean \pm SD & $1.5 \pm 0.7$ & $1.6 \pm 0.6$ & \\
\hline Range (min-max) & $(0-3)$ & $(1-3)$ & \\
\hline Total number of relapses & & & 0.371 \\
\hline Mean \pm SD & $3.1 \pm 1.9$ & $2.1 \pm 1.4$ & \\
\hline Range (min-max) & $(1-8)$ & $(1-6)$ & \\
\hline EDSS & & & 0.970 \\
\hline Mean \pm SD & $2.89 \pm 1.3$ & $2.95 \pm 1.6$ & \\
\hline Range (min-max) & $(1-5)$ & $(1-7)$ & \\
\hline Immunomodulatory therapy no. (\%) & & & $0.045^{*}$ \\
\hline Monthly methylprednisolone & $17(56.7 \%)$ & $21(70 \%)$ & \\
\hline Intramuscular interferon beta-1a & $7(23.3 \%)$ & $1(3.3 \%)$ & \\
\hline Subcutaneous interferon beta-1b & $2(6.7 \%)$ & $6(20 \%)$ & \\
\hline Subcutaneous interferon beta-1a & $4(13.3 \%)$ & $2(6.7 \%)$ & \\
\hline
\end{tabular}

MS Multiple Sclerosis, EDSS Expanded Disability Status Scale

${ }^{*} P$ value $<0.05$ (significant)

repeated relapses in MS patients lead to exhaustion of BDNF growth promotion, sensitivity, and efficacy and at the end resulting in the decrease in its levels.

On the other hand, Petereit and colleagues [22] and Liguori and colleagues [23] studied the role of BDNF in RRMS during remission and without the influence of immunosuppressive or immunomodulatory medications. They found higher blood levels of BDNF in MS patients in remission compared to healthy controls.

The difference between results can be explained by the following: some studies included MS patients of different subtypes including relapsing-remitting, secondary progressive, and primary progressive, whereas our study included only RRMS patients, there is a difference in the numbers of patients included and a difference in disease severity; also, the effect of immunosuppressive or immunomodulatory medications could not be totally eliminated in all studies and this may influence BDNF level.

In our study, there was no significant correlation between different MS patients' characteristics including the age of patients, age of onset, disease duration, number of relapses in the last 2 years, and total number of relapses with BDNF level.

Similar to our findings, Liguori and colleagues [8] and Comini-Frota and colleagues [17] found no correlation between age of patients or disease duration with BDNF level. Also, Pan and colleagues [24], Caggiula and colleagues [25], and Sarchielli and colleagues [26] reported that neither gender nor age correlations were found with BDNF level in RRMS patients.

Table 3 The BDNF level for MS patients in remission, MS patients in relapse, and control groups

\begin{tabular}{|c|c|c|c|c|c|c|c|c|c|c|}
\hline & \multicolumn{3}{|c|}{ MS cases in remission $(n=30)$} & \multicolumn{3}{|c|}{ MS cases in relapse $(n=30)$} & \multicolumn{3}{|c|}{ Control $(n=30)$} & \multirow[t]{2}{*}{$P$ value } \\
\hline & Median & Q1 & Q3 & Median & Q1 & Q3 & Median & Q1 & Q3 & \\
\hline BDNF (pg/ml) & 225 & 200 & 325 & 310 & 250 & 950 & 248 & 220 & 325 & $0.006^{*}$ \\
\hline
\end{tabular}




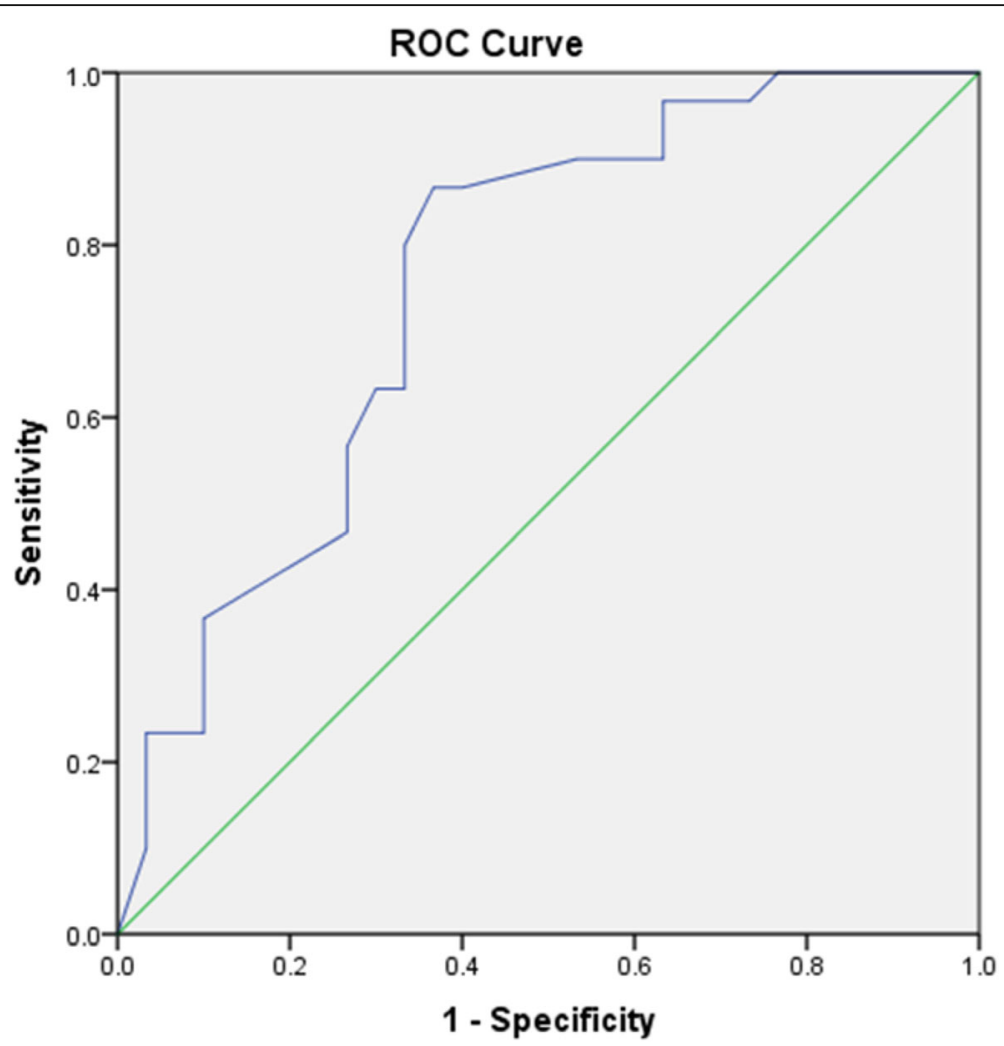

Fig. 1 ROC curve analysis to assess the sensitivity and specificity of BDNF in predicting MS disease activity

The cumulative disability in MS has a major negative impact on the quality of life of the patients [27]. In our study, there was no statistically significant correlation between the neurological disability measured by EDSS and BDNF level.

In accordance with our findings, Liguori and colleagues [8] and Comini-Frota and colleagues [17] revealed that there was no correlation between EDSS and BDNF level during the observational period of their RRMS patients. On the other hand, Yoshimura and colleagues [28] found that higher BDNF levels were associated with reduced disability in their MS cohort. The difference between results may be attributed to the selection of patients in a stable clinical phase of the disease (during remission) while our patients included relapse and remission groups.

MRI is a mandatory marker for the diagnosis and assessment of disease activity and progression in patients with MS [29]. Compared to other MRI findings, the load of T2 lesions is considered to be the best marker of MS

Table 4 Correlation between different characteristics of MS patients and BDNF level

\begin{tabular}{|c|c|c|c|c|}
\hline & BDNF level (pg & on group) & BDNF level (pg & e group) \\
\hline & (r) coefficient & $P$ value & (r) coefficient & $P$ value \\
\hline Age & 0.032 & 0.767 & 0.076 & 0.689 \\
\hline Age of onset & -0.017 & 0.898 & 0.123 & 0.519 \\
\hline Disease duration & -0.144 & 0.273 & -0.036 & 0.848 \\
\hline Number of relapses in the last 2 years & -0.159 & 0.224 & -0.137 & 0.721 \\
\hline Total number of relapses & -0.158 & 0.227 & -0.099 & 0.601 \\
\hline EDSS & -0.140 & 0.287 & -0.056 & 0.767 \\
\hline Number of supratentorial lesions in MRI & -0.116 & 0.376 & -0.007 & 0.973 \\
\hline Number of infratentorial lesions in MRI & 0.098 & 0.457 & $0.402^{*}$ & $0.028^{*}$ \\
\hline Number of spinal cord lesions in MRI & -0.080 & 0.541 & -0.130 & 0.494 \\
\hline
\end{tabular}

$B D N F$ brain-derived neurotrophic factor, EDSS Expanded Disability Status Scale ${ }^{*} P$ value $<0.05$ (significant) 
Table 5 Comparison between patients administered different drugs for MS regarding BDNF level

\begin{tabular}{|c|c|c|c|c|c|c|c|c|}
\hline \multirow[t]{2}{*}{ Drugs } & \multicolumn{4}{|c|}{ BDNF level (pg/ml) (remission group) } & \multicolumn{4}{|c|}{ BDNF level (pg/ml) (relapse group) } \\
\hline & Median & Q1 & Q3 & $P$ value & Median & Q1 & Q3 & $P$ value \\
\hline Monthly methylprednisolone & 220 & 175 & 245 & 0.617 & 325 & 255 & 950 & 0.792 \\
\hline Intramuscular Interferon beta-1a & 275 & 205 & 325 & & 250 & 250 & 250 & \\
\hline Subcutaneous Interferon beta- $1 \mathrm{~b}$ & 265 & 205 & 325 & & 268 & 245 & 1500 & \\
\hline Subcutaneous interferon beta-1a & 223 & 213 & 2613 & & 2608 & 215 & 5000 & \\
\hline
\end{tabular}

$B D N F$ brain-derived neurotrophic factor

activity and in long-term follow-up; it has a good correlation with disease severity and disability [30]. Mechanisms of neuronal repair act up to a threshold above which the repair cannot continue and this threshold correlates with the lesions load on T2 [31].

In our study, there was a positive linear correlation between the number of T2 infratentorial lesions in MS patients in relapse with BDNF level. In accordance with our findings, Sarchielli and colleagues found a positive correlation between the levels of BDNF and disease activity, confirmed by the presence of gadoliniumenhancing lesions in their MS patients [14].

The number of lesions in the infratentorial region is an important factor to predict the disease severity and the long-term disability in MS patients. The specific structure of the infratentorial area regarding high density of neural fibers can explain the finding that the correlation between clinical outcomes and MRI findings in the infratentorial region is more strong than other areas of the brain [32].

While Liguori and colleagues [8] found no significant correlation between the baseline BDNF values and the volume of white or gray matter in RRMS patients, on the other hand, Comini-Frota and colleagues [17] reported a negative correlation between serum levels of BDNF and the number of T2/FLAIR hyperintense lesions in MS patients.

The difference between results may be attributed to the fact that it was not possible to stratify the sample and to control the effect of immunomodulatory or immunosuppressive medications on BDNF levels. The number of MS patients enrolled in each study was different. Also, manual counting of MRI lesions is not the most accurate form to measure the burden of demyelinating lesions, but it is the most feasible one in clinical practice.

The aim of the current MS treatment is to target the inflammatory cascade, decrease the number of relapses and inflammatory lesions on MRI, and suppress the proinflammatory cytokines in the blood [33].

Our study found no correlation between patients administered different immunomodulatory therapy for MS either in the relapse or in the remission group and the serum level of BDNF. Immunomodulatory therapy in our patients included monthly IV methylprednisolone, IM interferon beta-1a, SC interferon beta-1b, and SC interferon beta-1a.

In accordance with our findings, Petereit and colleagues [22] revealed that interferon-beta had no effect on in vitro BDNF secretion in MS. Also, Hamamcioglu and Reder [33] and Liguori and colleagues [8] found that IFN-b, in vitro or in vivo, had no additional effect on BDNF production in MS patients.

On the other hand, other studies revealed increased serum BDNF levels in multiple sclerosis patients during interferon beta therapy $[25,28,34,35]$. The difference between results may be attributed to the different sample sizes, noncompliance of patients, half of our patients were in relapse, and some of them received monthly methylprednisolone.

The limitation of this study is the relatively small number of patients due to financial issues. A separate study should be done to evaluate the serum level of $\mathrm{BDNF}$ in a primary progressive type of multiple sclerosis.

\section{Conclusion}

The serum level of BDNF was significantly higher in RRMS patients in relapse compared to those in remission. Attention should be paid to the link between serum BDNF level as a neuroprotective factor and multiple sclerosis; it can be a biomarker for MS activity in the near future.

\section{Abbreviations \\ BDNF: Brain-derived neurotrophic factor; CNS: Central nervous system; EDSS: Expanded Disability Status Scale; FLAIR: Fluid-attenuated inversion recovery; MRI: Magnetic resonance imaging; MS: Multiple sclerosis; OD: Optical density; RRMS: Relapsing-remitting multiple sclerosis}

\section{Acknowledgements}

Not applicable

Authors' contributions

$\mathrm{MO}$ participated in the study design, sequence alignment, and analysis of the data and helped to draft the manuscript. HE participated in the study design, sequence alignment, and analysis of the data and helped to draft the manuscript. SA performed the laboratory work and helped to draft the manuscript. EA participated in the study design and collection of the data and helped to draft the manuscript. All authors read and approved the final manuscript. 


\section{Funding}

The authors did not receive any funding for this work.

\section{Availability of data and materials}

The datasets used and/or analyzed during the current study are available from the corresponding author on reasonable request with the permission of the Faculty of Medicine, Beni-Suef University, Egypt.

\section{Declarations}

\section{Ethics approval and consent to participate}

A written informed consent was obtained from each participant in this study, and the study was approved by the authorized ethical committee in the Faculty of Medicine, Beni-Suef University (FWA00015574 on 3 July 2018).

\section{Consent for publication}

Not applicable

\section{Competing interests}

The authors declare that they have no competing interests.

\section{Author details}

${ }^{1}$ Neurology Department, Beni-Suef University, Beni-Suef 62511, Egypt.

${ }^{2}$ Clinical Pathology Department, Beni-Suef University, Beni-Suef, Egypt.

\section{Received: 27 October 2020 Accepted: 3 March 2021}

\section{Published online: 16 March 2021}

\section{References}

1. Karussis D. The diagnosis of multiple sclerosis and the various related demyelinating syndromes: a critical review. J Autoimmun. 2014;48-49:13442.

2. Lucchinetti CF, Popescu BF, Bunyan RF, Moll NM, Roemer SF, Lassmann H, et al. Inflammatory cortical demyelination in early multiple sclerosis. N Engl J Med. 2011;365(23):2188-97. https://doi.org/10.1056/NEJMoa1100648.

3. Leibrock J, Lottspeich F, Hohn A, Hofer M, Hengerer B, Masiakowski P, Thoenen H, Barde YA. Molecular cloning and expression of brain-derived neurotrophic factor. Nature. 1989;341(6238):149-52. https://doi.org/10.103 8/341149a0

4. Gligoroska JP, Manchevska S. The effect of physical activity on cognition physiological mechanisms. Mater Sociomed. 2012;24(3):198-202. https://doi. org/10.5455/msm.2012.24.198-202.

5. Stadelmann C, Kerschensteiner M, Misgeld T, Brück W, Hohlfeld R, Lassmann H. BDNF and gp145trkB in multiple sclerosis brain lesions: neuroprotective interactions between immune and neuronal cells? Brain. 2002;125(Pt 1):7585. https://doi.org/10.1093/brain/awf015.

6. Reichardt LF. Neurotrophin-regulated signalling pathways. Philos Trans R Soc Lond B Biol Sci. 2006;361(1473):1545-64. https://doi.org/10.1098/rstb.2 006.1894 .

7. Laske C, Stransky E, Leyhe T, Eschweiler GW, Maetzler W, Wittorf A, Soekadar S, Richartz E, Koehler N, Bartels M, Buchkremer G, Schott K. BDNF serum and CSF concentrations in Alzheimer's disease, normal pressure hydrocephalus and healthy controls. J Psychiatr Res. 2007;41(5):387-94. https://doi.org/10.1 016/j.jpsychires.2006.01.014

8. Liguori M, Fera F, Patitucci A, Manna I, Condino F, Valentino P, Telarico P, Cerasa A, Gioia MC, di Palma G, Quattrone A. A longitudinal observation of brain-derived neurotrophic factor mRNA levels in patients with relapsingremitting multiple sclerosis. Brain Res. 2009;1256:123-8. https://doi.org/10.1 016/j.brainres.2008.11.047

9. Vondran MW, Clinton-Luke P, Honeywell JZ, Dreyfus CF. BDNF+/- mice exhibit deficits in oligodendrocyte lineage cells of the basal forebrain. Glia. 2010;58(7):848-56. https://doi.org/10.1002/glia.20969.

10. Thompson AJ, Banwell BL, Barkhof F, Carroll WM, Coetzee T, Comi G, Correale J, Fazekas F, Filippi M, Freedman MS, Fujihara K, Galetta SL, Hartung HP, Kappos L, Lublin FD, Marrie RA, Miller AE, Miller DH, Montalban X, Mowry EM, Sorensen PS, Tintoré M, Traboulsee AL, Trojano M, Uitdehaag BMJ, Vukusic S, Waubant E, Weinshenker BG, Reingold SC, Cohen JA. Diagnosis of multiple sclerosis: 2017 revisions of the McDonald criteria. Lancet Neurol. 2018;17(2):162-73. https://doi.org/10.1016/S1474-4422(17)304 70-2.
11 Kurtzke JF. Rating neurologic impairment in multiple sclerosis: an expanded disability status scale (EDSS). Neurology. 1983:33(11):1444-52. https://doi. org/10.1212/WNL.33.11.1444.

12. Bruck W, Stadelmann C. The spectrum of multiple sclerosis: new lessons from pathology. Curr Opin Neurol. 2005;18(3):221-4. https://doi.org/10.1097/ 01.wCo.0000169736.60922.20.

13. Kerschensteiner M, Stadelmann C, Dechant G, Wekerle H, Hohlfeld R. Neurotrophic cross-talk between the nervous and immune systems: implications for neurological diseases. Ann Neurol. 2003;53(3):292-304. https://doi.org/10.1002/ana.10446.

14. Sarchielli P, Greco L, Stipa A, Floridi A, Gallai V. Brain-derived neurotrophic factor in patients with multiple sclerosis. J Neuroimmunol. 2002;132(1-2): 180-8. https://doi.org/10.1016/S0165-5728(02)00319-3.

15. Frota ER, Rodrigues DH, Donadi EA, Brum DG, Maciel DR, Teixeira AL. Increased plasma levels of brain derived neurotrophic factor (BDNF) after multiple sclerosis relapse. Neurosci Lett. 2009;460(2):130-2. https://doi.org/1 0.1016/j.neulet.2009.05.057.

16. Azoulay D, Vachapova V, Shihman B, Miler A, Karni A. Lower brain-derived neurotrophic factor in serum of relapsing remitting MS: reversal by glatiramer acetate. J Neuroimmunol. 2005;167(1-2):215-8. https://doi.org/1 0.1016/j.jneuroim.2005.07.001.

17. Comini-Frota ER, Rodrigues DH, Miranda EC, Brum DG, Kaimen-Maciel DR, Donadi EA, Teixeira AL. Serum levels of brain-derived neurotrophic factor correlate with the number of T2 MRI lesions in multiple sclerosis. Braz J Med Biol Res. 2012;45(1):68-71. https://doi.org/10.1590/S0100-879X20110075001 65.

18. Kalinowska-Łyszczarz A, Pawlak MA, Wyciszkiewicz A, Osztynowicz K, Kozubski W, Michalak S. Immune-cell BDNF expression in treatment-naïve relapsing-remitting multiple sclerosis patients and following one year of immunomodulation therapy. Neurol Neurochir Pol. 2018;52(4):483-9. https://doi.org/10.1016/j.pjnns.2018.03.006

19. Azoulay D, Urshansky N, Karni A. Low and dysregulated BDNF secretion from immune cells of MS patients is related to reduced neuroprotection. $J$ Neuroimmunol. 2008;195(1-2):186-93. https://doi.org/10.1016/j.jneuroim.2 008.01.010.

20. kint M, Heyman EM, Meeusen R. Neuroplasticity - exercise-induced response of peripheral brain-derived neurotrophic factor: a systematic review of experimental studies in human subjects. Sports Med. 2010;40(9):765-801. https://doi.org/10.2165/11534530-000000000-00000.

21. Al-Temaimi R, AbuBaker J, Al-Khairi I, Alroughani R. Remyelination modulators in multiple sclerosis patients. Exp Mol Pathol. 2017;103(3):23741. https://doi.org/10.1016/j.yexmp.2017.11.004.

22. Petereit HF, Lindemann H, Schoppe S. Effect of immunomodulatory drugs on in vitro production of brain-derived neurotrophic factor. Mult Scler. 2003; 9(1):16-20. https://doi.org/10.1191/1352458503ms869oa.

23. Liguori M, Fera F, Gioia MC, Valentino P, Manna I, Condino F, Cerasa A, la Russa A, Clodomiro A, Paolillo A, Nisticò R, Vercillo L, Cittadella R, Quattrone A. Investigating the role of brain-derived neurotrophic factor in relapsingremitting multiple sclerosis. Genes Brain Behav. 2007:6(2):177-83. https://doi. org/10.1111/j.1601-183X.2006.00245.x.

24. Pan W, Banks WA, Fasold MB, Bluth J, Kastin AJ. Transport of brain-derived neurotrophic factor across the blood-brain barrier. Neuropharmacology. 1998;37(12):1553-61. https://doi.org/10.1016/S0028-3908(98)00141-5.

25. Caggiula M, Batocchi AP, Frisullo G, Angelucci F, Patanella AK, Sancricca C, Nociti $V$, Tonali PA, Mirabella M. Neurotrophic factors in relapsing remitting and secondary progressive multiple sclerosis patients during interferon beta therapy. Clin Immunol. 2006;1 18(1):77-82. https://doi.org/10.1016/j.clim.2005. 09.005 .

26. Sarchielli P, Zaffaroni M, Floridi A, Greco L, Candeliere A, Mattioni A, Tenaglia S, di Filippo M, Calabresi P. Production of brain-derived neurotrophic factor by mononuclear cells of patients with multiple sclerosis treated with glatiramer acetate, interferon-beta 1a, and high doses of immunoglobulins. Mult Scler. 2007;13(3):313-31. https://doi.org/10.1177/1352458506070146.

27. Fernández-Jiménez E, Arnett PA. Impact of neurological impairment, depression, cognitive function and coping on quality of life of people with multiple sclerosis: a relative importance analysis. Mult Scler. 2015:21(11): 1468-72. https://doi.org/10.1177/1352458514562439.

28. Yoshimura S, Ochi H, Isobe N, Matsushita T, Motomura K, Matsuoka T, Minohara M, Kira Jl. Altered production of brain-derived neurotrophic factor by peripheral blood immune cells in multiple sclerosis. Mult Scler. 2010; 16(10):1178-88. https://doi.org/10.1177/1352458510375706. 
29. Amato MP, Portaccio E, Goretti B, Zipoli V, Battaglini M, Bartolozzi ML, Stromillo ML, Guidi L, Siracusa G, Sorbi S, Federico A, de Stefano N. Association of neocortical volume changes with cognitive deterioration in relapsing-remitting multiple sclerosis. Arch Neurol. 2007;64(8):1157-61. https://doi.org/10.1001/archneur.64.8.1157.

30. Rudick RA, Lee JC, Simon J, Fisher E. Significance of T2 lesions in multiple sclerosis: a 13-year longitudinal study. Ann Neurol. 2006;60(2):236-42. https://doi.org/10.1002/ana.20883.

31. Barkhof $F$. The clinico-radiological paradox in multiple sclerosis revisited. Curr Opin Neurol. 2002;15(3):239-45. https://doi.org/10.1097/00019052-2002 06000-00003.

32. Almutairi A, Hassan $\mathrm{H}$, Suppiah $\mathrm{S}$, Alomair $\mathrm{O}$, Alshoaibi A, Almutairi $\mathrm{H}$, et al. Lesion load assessment among multiple sclerosis patient using DIR, FLAIR, and T2WI sequences. Egypt J Radiol Nucl Med. 2020;51(1):209. https://doi. org/10.1186/s43055-020-00312-0.

33. Hamamcioglu K, Reder AT. Interferon-beta regulates cytokines and BDNF: greater effect in relapsing than in progressive multiple sclerosis. Mult Scler. 2007;13(4):459-70. https://doi.org/10.1177/1352458506069672.

34. Lalive PH, Kantengwa S, Benkhoucha M, Juillard C, Chofflon M. Interferonbeta induces brain-derived neurotrophic factor in peripheral blood mononuclear cells of multiple sclerosis patients. J Neuroimmunol. 2008; 197(2):147-51. https://doi.org/10.1016/j.jneuroim.2008.04.033.

35. Mehrpour M, Akhoundi FH, Delgosha M, Keyvani H, Motamed MR, Sheibani B, Meysamie A. Increased serum brain derived neurotrophic factor in multiple sclerosis patients on interferon-b and its impact on functiona abilities. Neurologist. 2015;20(4):57-60. https://doi.org/10.1097/NRL. 0000000000000053.

\section{Publisher's Note}

Springer Nature remains neutral with regard to jurisdictional claims in published maps and institutional affiliations.

\section{Submit your manuscript to a SpringerOpen ${ }^{\circ}$ journal and benefit from:}

- Convenient online submission

- Rigorous peer review

- Open access: articles freely available online

High visibility within the field

- Retaining the copyright to your article

Submit your next manuscript at $\boldsymbol{\nabla}$ springeropen.com 